\title{
Young adults and everyday-life information: The role of news media th
}

\author{
Kirsty Williamson ${ }^{\mathrm{a}, *}$, Asim Qayyum ${ }^{\mathrm{b}}$, Philip Hider ${ }^{\mathrm{b}}$, Ying-Hsang Liu ${ }^{\mathrm{b}}$ \\ a Monash University, Caulfield, VIC, Australia \\ b School of Information Studies, Charles Sturt University, Wagga Wagga, NSW, Australia
}

\section{A R T I C L E I N F O}

Available online 4 August 2012

\begin{abstract}
A B S T R A C T
There is a paucity of research examining the everyday-life information seeking of young people, especially investigating the role that the news media has in providing information to young people for use in their everyday lives. A qualitative, interpretivist approach is adopted, involving 34 students, ages 18 to 25, from an Australian university. First, 20 students were interviewed about their news seeking (including topics and sources). Then 14 students participated in verbal protocol analysis, which involved a series of tasks concerning online and print newspapers. Lastly, students were interviewed about how they sought everyday-life information and whether they thought that they had incidentally acquired or encountered information on everyday-life topics in online or print newspapers in the recent past. Findings indicated that, contrary to expectations, traditional print media still played a role for young people, and social media were perceived as important for communication with friends, rather than for news gathering. Purposeful information seeking was more likely to occur online, but both print and online newspapers retained an incidental role in providing information to students for their everyday lives. Participants used a range of media to suit their particular needs and purposes. Thus, access to a wide variety of sources is important for everyday-life information seeking (ELIS) by young people.
\end{abstract}

(c) 2012 Elsevier Inc. All rights reserved.

\section{Introduction}

The 1990s brought a surge of interest in information seeking in relation to everyday-life information, particularly as a result of the publication of Savolainen's (1995) seminal article, which focused on two different groups of citizens, teachers and industrial workers. As others had done beforehand, for example, Chen and Hernon (1982), Savolainen explored the importance of the mass media in providing citizens with information for their everyday lives. Since that time, the range of available news sources has grown exponentially. A wide range of online media, providing a plethora of dynamic and free news sites, has been added to the traditional options of newspapers, radio, and television. In this new environment, traditional newspapers have been forced to provide online versions. The online user is more than ever not bound to a single news outlet and can move to a different site with just a click of a button. News aggregators now gather news reports from various sources and filter them down to the users according to their interests, thus transferring control to the news reader. These aggregators have ensured their success by attaching themselves to popular existing sites, for example, email providers. Social networking has added yet another dimension. The role of the media in the provision of information for everyday life is likely

\footnotetext{
is Based in part on News Seeking: Young Adults and Everday Life Information, presented by the authors at the i3 Conference, held at Robert Gordon University, Aberdeen, Scotland, June 20-23, 2011.

* Corresponding author.

E-mail address: kirsty.williamson@monash.edu (K. Williamson).
}

to be affected by these developments in news and communication media, particularly in the case of young people who are known to be attracted to the online environment.

\section{Problem statement}

In the context of this new, dynamic media environment, the news-gathering behavior of a sample of university students ages 18 to 25 attending an Australian regional university is explored. A particular focus is the role played by the current range of media options in the ELIS of the participants. Although the role of the media in informing people for their everyday lives is well documented in the literature (e.g., Nguyen \& Western, 2007; Savolainen, 1995; Williamson, 1998), much of existing research was undertaken in a much more limited media environment. Moreover, there is little research that examines the ELIS of young adults. Agosto and Hughes-Hassell (2005) made a contribution, but the age group they targeted was teenagers ages 14 to 17 . The ELIS of the very young was also explored by Chelton and Cool (2007). While the news-seeking behaviors of young adults in their late teens and early 20s are widely reported in the literature (e.g., Armstrong \& Collins 2009; Qayyum et al., 2010; Raeymaeckers, 2004), the media's role in ELIS for this age group requires more explicit exploration.

Apart from filling gaps in the literature, this research is significant because of the recent advent of social networking and the attraction of young adults to this new medium. One study, carried out over three years and involving more than 800 youth, found that social 
network sites and other supporting tools are now fixtures of youth culture (Ito et al., 2008). Young Internet users are also attracted to the user control enabled by Web environments (Huang, 2009). Youth appear to have a special influence on the continuing evolution of news delivery. In addition, the teens who recently turned into young adults have had limited encounters with traditional newspaper print-based subscriptions (Qayyum et al., 2010).

Thus, the research questions relate to the role of the media in informing young people for their everyday lives:

1. What is the impact on ELIS of the news types and topics chosen by young people?

2. How is ELIS affected by the extent of news gathering through online media, printed newspapers, and television and radio?

3. What is the effect on ELIS of the use of social networking tools for news seeking and news generation?

4. To what extent do young people purposefully seek, or acquire incidentally, everyday life information in print and online newspapers?

Answers to the first three questions are important to understanding the extent to which young people are informed for their everyday lives, as proposed by Savolainen (1995). The fourth question involves purposeful information seeking, as well as perceptions of the extent of incidental information acquisition (Williamson, 1998), or information encountering (Erdelez, 1997) by young people, thus directly addressing their ELIS behavior.

\section{Literature review and conceptual framework}

The relevant literature falls into two different areas. The first is concerned with research about young people and the media, including types of news topics of interest, and the kinds of news sources most often used, particularly what factors influence their selection. The second area is concerned with everyday-life information in general, along with its conceptualization for this research.

\subsection{Youth and the news media}

There is an overall decline in use of traditional news sources in the United States, with people in their late teens and 20s being in the vanguard of this trend (Ahlers, 2006). Ahlers (2006) and Nguyen and Western (2007) both noted that those under 40 years old were more likely than older generations to use online services. Ahlers concluded that print media are losing younger readers because of a lack of focus on their needs and interests, which appears to be confirmed by the trend of publishers to direct youth-related investment into online services (Graybeal, 2008; Kohl, 2008).

\subsection{News interests of young people}

What, then, does the literature reveal about the news interests of young people? Surveying young people between the ages of 15 and 30 , Huang (2009) found them to be most interested in reading about sports (46\%), world news (43\%), local news (43\%), and entertainment news (34\%). Raeymaeckers (2004) survey of 1200 Belgian students found that the students wanted a mix of entertainment and hard news, with local news of immediate relevance more highly valued than economics or politics, although the educational level had a strong impact. Raeymaeckers found that the perception that newspaper content is relevant to the lives of its readers was important to its credibility. This finding was confirmed by Armstrong and Collins (2009) in their survey of more than 1900 University of Florida students. Relevance of news to young people's lives appears to be very important in stimulating their interest, and for informing them on topics of relevance to their everyday lives, as Qayyum et al. (2010) found.

\subsection{News sources of choice}

Despite the pessimistic assessments of the role of traditional media in young people's lives, these cited studies have brought more heartening news regarding traditional news sources. Issues of trust and credibility have been especially prominent. For example, the young people in Huang's (2009) study had more trust in information provided through the Web sites of established news sources than in other sites. Among Raeymaeckers' students, 48\% thought that newspapers offered more complete information than television (Raeymaeckers, 2004). Kiousis' (2001) survey of more than 800 American university students found that newspapers were rated more credible than television or online news. Armstrong and Collins (2009) found that, although the students in their sample were less likely to read a newspaper, they were more likely to find it credible than the older generation. They also found that "students whose parents encouraged them to read a newspaper found [them] more credible than did their peers" (Armstrong \& Collins, 2009, p. 97). Parental influence appears to be important, with Raeymaeckers (2004), Huang (2009), and Qayyum et al. (2010) also finding that it had a significant impact on young people's attitudes to print newspaper reading.

Another key influence over choice of media channel has been found to be perceived depth of reporting-that is, whether the purpose is for entertainment, relaxation, or to acquire specific information. Huang (2009) found that his students read long stories less than once a week, and then only if they were very interested in the topic. Shorter articles were also preferred by students, who often read to reduce boredom, as a habit, or for relaxation (Raeymaeckers, 2004). Although not specific to young people, Flavian and Gurrea's (2006b) survey of 250 Spanish online newspaper readers found a concentration on specific subjects that were fairly rapidly accessed, particularly in the initial moments of reading. In contrast, printed newspapers were typically read more thoroughly, and in a more relaxed manner, mostly on weekends (Flavian \& Gurrea, 2006a).

Other key influences over media choices made by young people have included the degree of control over the media experience, and the ability to customize services to suit their life styles. Spyridou and Veglis (2008) found that the Greek journalism students in their sample liked to have control over their media experience, and therefore preferred the Internet. Huang's (2009) students similarly wanted control: news on demand according to their stipulations, where and when they wanted it. Nevertheless, Huang noted that his participants were interested in being informed citizens (Huang, 2009).

With regard to the influence of Web 2.0 and other kinds of communication tools, Schwartz (2005) found that blogs, podcasts, and streaming media were attractive to young readers. Zaphiris and Sarwar (2006) found that teens favored decentralized, peer-to-peer communication in their use of news groups in the United States, while older adults accepted dissemination of information by a small number of more knowledgeable contributors. Ito et al. (2008) found that online spaces enabled young people in the United States to experiment with the media and to interact with each other in new and different ways. It seems, therefore, that communication focused on personal interaction may be at least as important as information for young people in the online environment, although the question remains of how effective social networking tools are in disseminating news and informing young people for their everyday lives.

\subsection{Everyday-life information seeking}

The conceptualization of ELIS began with Savolainen's (1995) landmark theory. Savolainen introduced two new concepts: (1) "way of life" or the "order of things" resulting from "the choices that individuals make in everyday life" (p. 262); and (2) "mastery of life" or the "caring activity" required to produce a "meaningful order of things" (p. 264). In order to achieve "mastery of life", individuals monitor their world 
through electronic and print media, acquiring what Savolainen labeled as "orienting information," that is, information that concerns current events (p. 272) that is crucial for people in their everyday lives. Thus, understanding the news interests of young people is also crucial to understanding the extent to which they are gaining orienting information for their everyday lives. Savolainen's other dimension of ELIS is "practical information which serves as the solution to specific problems" (Savolainen, 1995, p. 272).

Another conceptual strand emerges from Williamson's (1995, 1997, 1998) work concerning the role of incidental information acquisition in informing people for their everyday lives. This is in addition to purposeful information seeking, which has been the major focus of theory and empirical research in the field. Williamson was influenced by P. Wilson's (1977) theory, which proposed the notion that people incidentally acquire information through monitoring their environment by personal observations, discussions with friends, relatives and colleagues, and by the use of the mass media. As Williamson's research indicated, an information need is not always perceived until information is actually encountered. Williamson found that interpersonal sources and the mass media were very important for her sample of 202 older adults, ages 60 and older. Other ways of describing nonpurposeful information acquisition include "passive attention" (T. D. Wilson, 1997) or "information encountering" (Erdelez, 1997). Bates (2002) proposed that "it is not unreasonable to guess that we absorb perhaps $80 \%$ of all our knowledge through simply being aware, being conscious and sentient in our social context and physical environment" (p. 4). Bates gave equal emphasis to the active and passive in her "modes of information seeking" (Bates, 2002, p. 4).

While it must be emphasized that a uses and gratifications framework was not undertaken here, this theory, which originated during the latter half of the 19th century (e.g., Frank \& Greenberg, 1980; Katz et al., 1974; McQuail, 1994) had some influence. In the early use of this theory, emphasis was on the differences that occur when comparisons are made among different media and types of content. Typically, early findings demonstrated that different kinds of media served different functions for individuals who actively chose both the content and medium that best suited their needs. Indeed, the notion of the "active audience" has become increasingly relevant, as Severin and Tankard (1992) predicted, given that people are being presented with more and more media choices. Recent uses of the theory include Savolainen (1999), who focused on the use of the Internet in information seeking, Dunne et al. (2010), who explored young people use of social networking sites, not from news or ELIS perspectives, and Huang (2009), who focused on the news seeking of young people, although without an emphasis on ELIS.

Early uses and gratifications studies of information and the mass media typically showed that users of print media were better informed than users of electronic media (Wade \& Schramm, 1969; Warner et al., 1973). A question that arises in the online context is how the decline in newspaper reading will affect the degree to which citizens, especially the young, are informed for their everyday lives.

\section{Method}

The approach of this research, which was undertaken in two phases over a two-year period, 2009 to 2010, was qualitative (interpretive) and broadly ethnographic, at least for the first phase where rich descriptions of participants' news seeking were sought. This in-depth approach was preferred to a survey, which would have resulted in a broader but shallower picture. The second phase involved verbal protocol analysis, only a small part of which is relevant here.

The sample included 34 students, aged 18 to 25 , studying at an Australian university, with 20 students taking part in the first phase, and 14 in the second. Sampling was partly purposive (with criteria being "age" and "interest in news"), and partly convenience. For the interest in news criterion, participants who actively read, listened to, or viewed news reports in any media or format were solicited. Those who took part were given an information sheet that provided details of the project, and signed a consent form, as required by the university's Human Research Ethics Committee. They also received a $\$ 30$ gift voucher.

The data collection involved two research instruments during the first phase: a semi-structured interview schedule and a demographic questionnaire. Both instruments were developed by the team and piloted with three appropriate young people. Minor adjustments were made to the demographic questionnaire, but the interview schedule was found to work satisfactorily. Questions focused on the various kinds of news of interest to students, the sources they used, and their perceptions of these sources, which included online media, printed newspapers, TV, radio, and social networking tools. Interviews took place during 2009, in the School of Information Studies' digital library laboratory, located inside the campus library. Interviews were recorded digitally, with the permission of the interviewees.

During the second phase, the verbal-protocol analysis in 2010, 14 students undertook six different tasks comparing online and print newspaper interfaces, and describing their thoughts and actions during the process. Interview questions were asked immediately after each task to seek the participant's opinions, thoughts, and motives behind the actions undertaken while completing the tasks. Only one of these tasks is relevant to the discussion here. That task centered on everyday-life information, where students were asked to explore newspapers to find information on everyday-life topics of interest to them, for example, health and consumer products. They then answered questions about their purposeful information seeking and about whether they thought that they had incidentally acquired or encountered information on everyday-life topics in online or print newspapers during the undertaking of the task, and/or in the recent past. This task, and the answers to the interview questions that followed, are analyzed here. Such a combination of concurrent and retrospective verbal protocol collection was preferred, as research by Kuusela and Paul (2000) demonstrated some distinct advantages of both techniques. The retrospective reporting was very beneficial for exploring ELIS of participants, as this activity was not a direct outcome of the task, but rather an associated one.

The data analysis for both phases was preceded by transcription of the audio recordings by trained transcription typists. The data from the first phase interviews were then analyzed using the NVIVO software program for the analysis of qualitative data. Major themes, and the categories within them, were developed through this software. The analysis of the concurrent verbal protocols from the task, and retrospective protocols from the interview questions on everyday-life information was undertaken by hand, with quotations linked to the themes and categories developed.

\section{Findings}

Stage 1 findings focus on the issues that affected participants' orienting information for everyday life. (It should be noted that Qayyum et al., 2010, provided a much more detailed account of the Stage 1 findings, although from the perspective of news gathering, not ELIS.) Stage 2 findings pertain to purposeful and incidental ELIS.

\subsection{Orienting information}

Orienting information, which Savolainen (2007) described as "cognitive and expressive elements that people employ to monitor everyday events or keep abreast of time," was the focus of findings of the first stage. How participants used the media was considered important for gauging the extent to which they were obtaining orienting information and an understanding of their world. Included were news types and topics of interest, preferences for news sources, and the reasons for those choices. 


\subsection{News types and topics of interest}

As indicated above, relevance of news to young people's lives appears to be very important in stimulating their interest (Armstrong \& Collins, 2009; Qayyum et al., 2010; Raeymaeckers, 2004) and for informing them about topics of relevance to their everyday lives. The choices of news types and topics appeared to steer the news seeking (and thus the orienting information acquired by participants) in particular directions, thus indicating the impact of these choices.

Local news was of highest interest to first-phase participants ( $N=$ $20 ; n=16$ ) because of its perceived relevance: "I like the local newspaper just because it comes up with local issues. I don't like to hear the tabloid stuff that's in the Sydney papers," and "I read the local section because it is really applicable to me now. There's events and stuff in town that I wouldn't hear of otherwise."

As reported in Qayyum et al. (2010), other important news types for the majority of the sample were world, national, and health news, with news about celebrities, environment and climate change, entertainment, and sports being of some interest to at least half the sample. At least one-quarter of the sample were interested in science and technology, which can be explained by the types of courses being pursued by some of the students, and employment, which is understandable, given that finding jobs would soon become important to many of them. As Raeymaeckers (2004) found, there was more interest in recreational and entertainment topics than in government and social issues.

With regard to topics of interest, again, relevance was the key. Thus, past involvement or experiences was an important determinant, for example, with sports news: "If there's anything on horses and stuff like that, I'll read it."

The potential impact on the students' own lives was an influence on topics of interest, as was the perceived relevance to their personal situations, studies, or interests, as the following quotations illustrate: "Things about the recession, where that's impacting most because that obviously goes to employment and things like that." "[I look for] science, because that's what I study."

\subsection{Preferences for news sources}

Once again, choices of news sources are likely to have had an impact on the ELIS of study participants. Recent studies have found that print newspapers still have high credibility among young people (e.g., Armstrong \& Collins, 2009; Kiousis, 2001; Raeymaeckers, 2004). This is particularly interesting in light of the findings of early uses and gratifications studies of information and the mass media, which typically showed that users of print media were better informed than users of electronic media (Wade and Schramm, 1969; Warner et al., 1973); electronic media in those days referred to radio and television.

Most students used a variety of sources, with some students stating that they valued a mix of sources because they thought it gave them a more well-rounded picture. Some participants identified one or two predominant sources, but these also varied. Internet news was a primary source for only a few, with others relying on print newspapers, television, radio, and word of mouth. Leading to the conclusion that using a particular news source or sources was not important to many in the sample were comments such as: "I wouldn't care [about the news source]. I just don't notice, really. I don't care." "It is not important for me to get the news specifically from anywhere, but it is important to get the news in general."

\subsection{Online news sources}

In contrast to the findings in the literature, for example, Spyridou and Veglis (2008), online news sources played minor roles in news gathering for the vast majority in the first stage, although 17 out of 20 used the Internet for news, at least occasionally. Most of the 17 did not actively seek news stories online; it was simply part of their browsing routine, as the following quotations attest: "I've got Hotmail and every time I sign into Hotmail I have to go past the [MSN] page and sometimes if there's an interesting story I'll press the link." "Internet is convenient because you go to check your email and then you check the news at the same time."

Most did not read online newspapers on a regular basis-"Not regularly. Only if there is something that comes up that I think is interesting or I think might affect me"-with technology as one reason why: "I haven't really used [online news] very much because we've got dial up at home, so it takes too long for anything to come through."

\subsection{Print newspapers}

Despite expectations to the contrary that were rooted in articles such as Ahlers (2006), print newspapers were read by 17 out of 20 participants, and were considered important by most students. Nevertheless, only four saw print newspapers as their top source. For some interviewees, reading print newspapers was part of their lifestyle: "I think so because for me reading [print newspaper] is a recreational activity." "I love reading when I come to the library, the newspapers every day."

Others read a print newspaper if it were available. Very often, this was in their home environment, where their parents purchased the newspapers. Influence of parents' newspaper habits was strong, as had previously been determined by Raeymaeckers (2004), and Huang (2009): "When I arrive back to Sydney there will be a newspaper at home, so I usually read it."

Physical convenience and comfort were seen as advantages. There were many comments about these attributes of print newspapers: "I'd probably still like the paper because you can take it anywhere, where you go." "That's the main reason [for reading print newspapers], convenience I guess."

\subsection{Television and radio}

Television news was watched by 15 participants and was the top source for nine. Radio was a news source for 14 , although it was the top source for only three students. Reasons why television's high ranking included the opportunity it gave for sharing news with others: "Well, I live in a house of a group of people, so in the morning that [TV] is kind of like one of the things that everyone will watch. So we sit down to have breakfast and that's just on. So we'll watch [TV]."

There were often similar reasons offered for the popularity of both TV and radio. One was convenience: "I can just be cooking and watching [TV]." Convenience with radio was associated with driving: "It's usually like I said, when I'm driving...It's like while I'm going somewhere. It's usually informative... about music events, festivals and things like that which I'm also interested in." "If I'm in the car, definitely when I'm driving I definitely listen to the radio."

Several participants mentioned that some news items on TV or radio could lead to further research using the Internet.

\subsection{Social networking and news}

Facebook, Flickr, Twitter, MSN Messenger, Myspace, YouTube, and blogs were investigated. Authors such as Schwartz (2005) and Ito et al. (2008) had led to the expectation that young adults would view social networking as very important. In fact, students clearly indicated that in general, social networking was not about news, but about interacting with friends. Only Facebook $(n=9)$ was used to any extent, mostly for communication, with some news mixed in, although the latter was often personal news, for example, news about friends: "I have lots of friends [on Facebook] so I go on and talk to them." "Celebrity news, entertainment news, sports news. When I say news, it's 
like when people put on their status: 'Oh New Zealand won last night."' "I suppose from blogs and Facebook and all those sorts of things, I get personal news that I find out from other people."

Mostly, the respondents' preference was for face-to-face news discussions, rather than on Facebook or blogs, with privacy being a key issue: "Well, mostly [a blog is] just one person going on and on about something that they care about." "Everyone can see what you write [on Facebook] so it's not really a place where I'd go if I want to have a talk."

\subsection{Credibility of news sources}

Confirming the findings of Raeymaeckers (2004) and Armstrong and Collins (2009), infrequent use of online sources appeared to be related to lack of trust and a perception that these Web sites lacked credibility. This was, in part, because of the unknown provenance of online sources, and the ease with which Web sites can be changed: "As much as there is a lot of reputable stuff [online], there is a whole heap of shonky stuff. I don't really trust the internet as much I do a piece of paper." "If someone puts something on the Internet, they don't have to have anyone checking it and making sure that they have done the right research, so I don't trust it too much."

Indeed, most participants trusted printed sources. Nevertheless, there was also trust in quality online sources, for example, major newspapers and TV sites: "The Web sites I go to, like MSN and Yahoo, I think they're just recycled stuff...but if I knew that [online news publishers] took the news from The Age or something like that, a decent newspaper, I would be more inclined to read it."

The orientation of participants to quality news sources, be they print or online, augurs well in terms of their ELIS.

\subsection{Everyday-life information seeking (ELIS)}

As Huang (2009) found, almost all participants in both stages were keen to be informed about their world, and saw media as playing an important part in this. Stage 1 participants clearly gathered much orienting information, or information about their world, and they saw it as important for daily living. Stage 2 participants located everyday-life information of interest to them in print and online newspapers during the task process of the research; they also answered questions about their purposeful information seeking and their incidental information acquisition (IIA) on topics important to their everyday lives. The second stage focuses on findings regarding purposeful and incidental ELIS.

\subsection{Source use for purposeful ELIS}

Although about half of second stage participants also preferredand read-print newspapers, the majority were more likely to use Google to find everyday-life information, than to check a newspaper, either in print or online. One student did not even know that newspapers offered sections on everyday-life information, for example, jobs: "I didn't even know until you pointed them out [during the task process]."

Topics on which interviewees had purposefully sought or incidentally acquired information included suicide statistics, rental properties, cars to buy, other consumer products, jobs, movies, death notices, travel, and finance.

There were many quotations from participants illustrating their use of the Internet for purposeful information seeking, with Google often being the place where the search began: "I would go on the Internet and go to a specific...Web site....and then check out (movie times)." "I know recently that I've used the Internet to look for a new car, to find rental properties and things like that. Rather than looking in the newspaper for those sort of things, I would probably look online." "If I'm about to buy something, I'd do that on the 'Net, because it's updated straightaway."

At times participants knew the exact web site they needed: "If I wanted to check what was on in Wagga, I would probably go to the Wagga Council Web site." "Not for a long time [have I used the newspaper for ELI]. When I look for say career stuff, I tend to look on specialist career sites [like] Seek or Career One."

While not as frequently used as the Internet for purposeful information seeking, newspapers were still important to some participants: "In the Wagga paper The Advertiser, I always look at that little section [on cars] they have, or the quick little notes there like house for rent or the job. I always look at the jobs that they have going." "Yeah, I would occasionally buy The Daily Advertiser, and look for employment...just recently I bought it and...[there were] people selling things, buying things, accommodation and just public notices." "I will always, always buy The Daily Telegraph over the weekend because I like the cars guide."

Although her participants were at the other end of the age spectrum, Williamson's (1995, 1997, 1998) 202 respondents, ages 60 and older, made considerable purposeful use of print newspapers. The availability of easy-to-use, often up-to-date online information, however, has inevitably eroded the use of print newspapers for purposeful information seeking. Online versions of newspapers were also used by some students for purposeful information seeking. One respondent felt that an online newspaper could have certain advantages: "[An] online [version of a newspaper] is better for...certain things that you specifically want to have a look at. Like I enjoy looking at just the health and science articles. Within the print version of the newspaper, I find more often than not, they're actually all spread out."

\subsection{Incidental information acquisition (IIA) from newspapers}

A key focus of Williamson's $(1995,1997,1998)$ work concerned the extent of incidental information acquisition (IIA) that occurred as her older adults monitored their world. Her study was undertaken prior to much awareness in the library and information science field that the acquisition of information was not just a result of purposeful seeking. About the same time, Erdelez (1997) undertook a study of browsing in libraries and coined the term "information encountering" to describe the serendipitous findings that took place. Williamson found that her participants were able to understand the concept of IIA as it was explained during the interviews, and that almost all of them could provide examples of either information they had found when they were not specifically seeking it, or of something they had unexpectedly learnt. Stage 2 participants were also able to understand the concept, and recalled examples that involved newspapers. Some of these were the result of undertaking the task where students perused print and online newspapers looking for any items that they thought would be helpful for their everyday lives.

After that task was completed, students were asked whether they had discovered information that might be useful: "Just the fact that this jumps out at me. I wouldn't go specifically, to a newspaper, or specifically to a site with the mindset to read about how many hours of sleep per night is best. But the fact that it's there, sort of impulsively, I would click on it." Others noted: "There were a few little things I picked up, like in the health and science [browsing task]," and, "Yeah, I think [that I encounter useful information in newspapers]." Other examples were provided from participants' memories: "Yeah, there's a new movie coming out. I forget what it's called. I saw that yesterday [when I was browsing the newspaper]. I think I was reading it's got Leonardo DiCaprio in it." Another said: "When I was kind of going through some articles and some stuff in the papers...I ended up coming across [information] about how the financial planning industry is changing] and finding out that it wasn't just my firm but it was actually a legislation change. So it gave me a bit more background information on that." 
It is interesting to note that a recent study (Borchuluun, 2011) found that some respondents were obtaining considerable amounts of information about news events through incidental exposure to online news, especially via the Web. Although this research was not specifically focused on young people, $70 \%$ of the sample was under 40 years of age.

\section{Discussion}

Several observations about the ELIS of the young people in the sample can be made. During Stage 1, the ways in which the participants used the media provided understanding about the kinds of orienting information to which they were exposed, for example, the kinds of news sources, and topics of interest. A number of unexpected findings emerged. The first was the high regard for print. This finding appears to be out-of-step with much of the literature (e.g., Mitchell, 2010; Pew Project for Excellence in Journalism, 2009), which sees traditional media as having a diminished role, especially for young people. An important explanation is likely to be the well-educated sample involved. It is a moot point, too, as to whether the outcomes were influenced by the fact that many of the students in the sample were from a rural area. A number of them lived in university accommodation or group housing, returning home on the weekends and holidays. This was where they often took advantage of their parents' print newspapers. The findings of other studies were confirmed: Media choices made by parents have considerable influence on their children's media use.

There is another possible explanation for the unexpected finding. The participants, although keen print newspaper readers, were also very much involved in online activity. This confirms the findings of researchers such as Ahlers (2006), Nguyen and Western (2007), and Buente and Robbin (2008): that most active users of online information are still substantial users of traditional media. Indeed, the second stage of the research revealed that purposeful seeking for everyday-life information was most likely to occur online for these respondents, while the acquisition of orienting information, which assisted participants to understand and relate to their world, was more likely to occur through the print media, television, and radio; news aggregators were also influential through the major e-mail Web sites. As uses and gratifications theory originally proposed, participants used a range of media to suit their needs and purposes. For young adults in particular, it seems that news has become less connected to particular sources. Therefore, it was not important for participants to gather news or everyday-life information from specific sources.

Huang cited Schwartz (2005) and Shields (2005) as examples of studies that show that "young people are still giving newspapers a chance" (Huang, 2009, p. 105). This research confirms that finding, and also suggests that people with higher education levels will be likely to continue to value print newspapers. When asked specifically, most second-stage participants acknowledged that print and/or online newspapers still played a role in informing them for their everyday lives. These are certainly indicators for newspapers to keep in mind, particularly the relevance of content, which has been shown to be very important to young people.

One of the most interesting findings is in regard to social networking tools. The students showed discernment with regard to tools such as Facebook, and blogs, which were seen as serving the purpose of communication or interaction with friends, rather than for news gathering. Indeed, the critical comments made about blogs in the first stage were borne out in the second stage, where one of the tasks involved comparing a formal journalist opinion piece to readers' opinions in newspaper blogs. Most students were skeptical of the value of the readers' opinions, and preferred the journalist's opinion piece. It seems that the samples in both stages were inclined toward quality sources of news and everyday-life information.

\section{Conclusion}

This research plays a part in filling two gaps in the literature. First, it addresses the paucity of research specifically focusing on the ELIS of young people, particularly those ages 18 to 25 . Secondly, it seeks to fill the gap in empirical research about the role of the media in informing people for their everyday lives, which has been opened up by the expanded media environment. Indeed, one reason for the significance of this research is the recent advent of social networking and the documented attraction of young adults to it.

A key finding was of considerable surprise: Participants saw traditional sources, including printed newspapers, as continuing to play a key role in informing them for their everyday lives. Moreover, the predominant view was that social networking is not about news gathering, but rather about social interaction. Purposeful information seeking is more likely to take place online, particularly through Google. However, information was acquired incidentally from both online and print newspapers.

Thus, although the range of media available continues to expand, this study indicates that traditional media, including print newspapers, are not being displaced by the online and social networking options now available. Rather, while online networking sites are permanent fixtures in the lives of young adults, activities such as reading print newspapers co-exist with online newspapers, as part of young people's routines for monitoring the world. Although the research is limited by the type of young adults included, and its exploratory nature, one response to the gaps in the literature has been provided. Given the dynamic nature of the environment involved, and the importance of the issues, especially to the newspaper industry, further research would be worthwhile, especially using samples of different kinds of young people.

\section{Acknowledgments}

The authors acknowledge, with thanks, Research Priority Area funding received for this project from the Faculty of Education, Charles Sturt University, Wagga Wagga, NSW.

\section{References}

Agosto, D. E., \& Hughes-Hassell, S. (2005). People, places, and questions: An investigation of the everyday life information-seeking behaviors of urban young adults. rLibrary \& Information Science Research, 27, 141-163.

Ahlers, D. (2006). News consumption and new electronic media. The Harvard International Journal of Press/Politics, 11(1), 29-52.

Armstrong, C. L., \& Collins, S. J. (2009). Reaching out: Newspaper credibility among young adult readers. Mass Communication and Society, 12(1), 97-114.

Bates, M. (2002). Toward an integrated model of information seeking and searching. The New Review of Information Behaviour Research, 3, 1-15.

Borchuluun, Y. (2011). Incidental exposure to online news. Proceedings of the American Society for Information Science and Technology, 47(1), 1-8.

Buente, W., \& Robbin, A. (2008). Trends in Internet information behavior, 2000-2004. Journal of the American Society for Information Science and Technology, 59, 1743-1760.

Chelton, M. K., \& Cool, C. (Eds.). (2007). Youth information seeking behaviors II: Context, theories, models, and issues. Lanham, MD: Scarecrow Press.

Chen, C., \& Hernon, P. (1982). Information seeking. New York, NY: Neal-Schuman.

Dunne, A., Lawlor, M., \& Rowley, J. (2010). Young people's use of online social networking sites-A uses and gratifications perspective. Journal of Research in Interactive Marketing, 4(1), 46-58.

Erdelez, S. (1997). Information encountering: A conceptual framework for accidental information seeking. In P. Vakkari, R. Savolainen, \& B. Dervin (Eds.), Information seeking in context (pp. 412-421). London, UK: Taylor Graham.

Flavian, C., \& Gurrea, R. (2006a). The choice of digital newspapers: Influence of reader goals and user experience. Internet Research, 16(3), 231-247.

Flavian, C., \& Gurrea, R. (2006b). The role of readers' motivations in the choice of digital versus traditional newspapers. Journal of Targeting, Measurement and Analysis for Marketing, 14(4), 325-335.

Frank, R. E., \& Greenberg, M. G. (1980). The public's use of television: Who watches and why. Beverly Hills, CA: Sage.

Graybeal, G. M. (2008). Youth 2.0: A study of resources used by newspapers to attract young readers. (Unpublished master's thesis). University of Georgia, Athens.

Huang, E. (2009). The causes of youths' low news consumption and strategies for making youths happy news consumers. Convergence: The International Journal of Research into New Media Technologies, 15(1), 105-122. 
Ito, M., Horst, H., Bittanti, M., Boyd, D., Herr-Stephenson, B., \& Lange, P. G. (2008). Living and learning with new media: Summary of findings from the digital youth project. Retrieved from http://www.citeulike.org/group/8357/article/6052834

Katz, E., Blumler, J. G., \& Gurevitch, M. (1974). Utilization of mass communication by the individual. In J. G. Blumler, \& E. Katz (Eds.), The uses of mass communication: Current perspectives on gratifications research (pp. 19-32). Beverly Hills, CA: Sage.

Kiousis, S. (2001). Public trust or mistrust? Perceptions of media credibility in the information age. Mass Communications and Society, 4(4), 381-403.

Kohl, J. (2008). Beyond the printed page: As newspapers move deeper into the mobile and online space, strategy checked in with Canada's national newspaper warriors to find out what's working. Strategy, 19(7), 27-29.

Kuusela, H., \& Paul, P. (2000). A comparison of concurrent and retrospective verbal protocol analysis. American Journal of Psychology, 113(3), 387-404.

McQuail, D. (1994). Mass communication theory: An introduction (3rd ed.). London, UK: Sage.

Mitchell, A. (2010). Revealing the digital news experience-For young and old Nieman Reports, 64(2). (pp. 27-30). Retrieved from http://www.nieman.harvard.edu/reports/ article/102406/Revealing-the-Digital-News-ExperienceFor-Young-And-Old.aspx

Nguyen, A., \& Western, M. (2007). Socio-structural correlates of online news and information adoption/use: Implications for the digital divide. Journal of Sociology, 43(2), 167-185.

Pew Project for Excellence in Journalism (2009). The state of the media: An annual report on American journalism. Washington, DC: The Author. Retrieved from http://www. stateofthemedia.org/2009/

Qayyum, M. A., Williamson, K., Liu, Y. -H., \& Hider, P. (2010). Investigating the new seeking behavior of young adults. Australian Academic \& Research Libraries, 41(3), 178-191.

Raeymaeckers, K. (2004). Newspaper editors in search of young readers: Content and layout strategies to win new readers. Journalism Studies, 5(2), 221-232.

Savolainen, R. (1995). Everyday life information seeking: Approaching information seeking in the context of "way of life". Library E' Information Science Research, 17, 259-294.

Savolainen, R. (1999). The role of the internet in information seeking. Putting the networked services in context. Information Processing and Management, 35, 765-782.

Savolainen, R. (2007). Media credibility and cognitive authority. The case of seeking orienting information. Information Research: An International Electronic Journal, 12(3). Retrieved from http://informationr.net/ir/12-3/paper319.html

Schwartz, M. (2005). Newspaper circulation woes offset by Internet gains: NAA says publishers should focus on audience reach rather than number of newspapers sold. $B$ to $B, 90$ (16), 3.

Severin, W. J., \& Tankard, J. W. (1992). Communication theories: Origins, methods and uses in the mass media (3rd ed.). New York, NY: Longman.

Shields, T. (September 26). Not all bad news: Web sites grow, but circ continues down [Special Report 20(1)]. Brandweek, 46(34).

Spyridou, P., \& Veglis, A. (2008). The contribution of online news consumption to critical-reflective journalism professionals: Likelihood patterns among Greek journalism students. Journalism, 9(1), 52-75.

Wade, S., \& Schramm, W. (1969). The mass media as sources of public affairs, science and health knowledge. Public Opinion Quarterly, 33, 197-209.

Warner, E. S., Murray, J., \& Palmour, V. E. (1973). Information needs of urban residents (Final Report No. OEC-0-71-455, ED088464): Regional Planning Council of Baltimore and Westat Inc. of Rockville, MD to the U.S. Department of Health, Education and Wel- fare, Office of Education, \& Division of Library Programs. Washington, DC: Government Printing Office.

Williamson, K. (1995). Older adults: Information, communication and telecommunications. (Unpublished doctoral dissertation), RMIT University, Melbourne, Australia.

Williamson, K. (1997). The information needs and information-seeking behaviour of older adults: An Australian study. In P. Vakkari, R. Savolainen, \& B. Dervin (Eds.) Information seeking in context (pp. 337-350). London, UK: Taylor Graham.

Williamson, K. (1998). Discovered by chance: The role of incidental learning acquisition in an ecological model of information use. Library and Information Science Research, 20(1), 23-40.

Wilson, P. (1977). Public knowledge, private ignorance. Westport, CT: Greenwood Press.

Wilson, T. D. (1997). Information: An interdisciplinary perspective. Information Processing \& Management, 33(4), 551-572.

Zaphiris, P., \& Sarwar, R. (2006). Trends, similarities, and differences in the usage of teen and senior public online newsgroups. ACM Transactions on ComputerHuman Interaction, 13(3), 403-422.

Kirsty Williamson has, since 1998, been director of the group Information and Telecommunications Needs Research, which spans Monash University and Charles Sturt University in Australia. Since 1990 she has received more than $\$ 3$ million in research grants, partly from industry but also considerable amounts from the Australian Research Council, the chief funding body of the universities in Australia. Her research has spanned a range of topics, with the emphasis on understanding and meeting user needs in the areas of information and technology.

Asim Qayyum completed his PhD at University of Toronto, Canada, and has experience working and teaching in the fields of information sciences and technologies in Asia, North and Central America, and now in Australia. Dr. Oayyum has several research awards to his credit, and has conducted research projects funded by national and institutional grants in the areas of human computer/document interaction, digital libraries, knowledge management, user needs, multicultural concerns, and learning technologies.

Philip Hider is head of the School of Information Studies at Charles Sturt University (CSU), Australia. He holds a master's in librarianship degree from the University of Wales, Aberystwyth, and a PhD from City University, London. He worked at the British Library from 1995 to 1997, in Singapore from 1997 to 2003, and has since worked at CSU, teaching and doing research primarily in the areas of information organization, retrieval and architecture.

Ying-Hsang Liu is a lecturer in information management at the School of Information Studies, Charles Sturt University, Australia. He holds a Ph.D. in information science from the School of Communication and Information at Rutgers University, New Jersey His primary research and teaching areas lie at the intersections of interactive information retrieval, the organization of information, and human information behavior, with an emphasis on usercentered information access system design and evaluation. 